\title{
Improvement of detectics through electronic resources in the educational process
}

\author{
Murodov Nodirbek Oybek Ogli ${ }^{1}$, Shuhratjon Durmenov Nurmamatovich ${ }^{2}$ \\ ${ }^{1}$ Student of the Faculty of Military Education of Tashkent State Pedagogical University named after Nizami, \\ Uzbekistan \\ ${ }^{2}$ Senior Lecturer Faculty of Military Education, Tashkent State Pedagogical University, Uzbekistan \\ Email:murodovnn@umail.uz
}

\begin{abstract}
This article is about analysis of modern educational electron publications showed that they have a complex structure and are autonomous to cassification. On the basis of the classification of electronic educational publications are general methods of both educational and electronic and software classification
\end{abstract}

Keywords: modern, educational, electron, publications, nature of basic information

\section{INTRODUCTION}

The analysis of modern educational electron publications showed that they have a complex structure and are autonomous to cassification. On the basis of the classification of electronic educational publications are general methods of both educational and electronic and software classification:

Educational publications are divided into the following types:

\# according to its functional nature, which determines its importance and location in the educational process;

\# according to the purpose;

\# according to the nature of the information provided;

* according to the organization of the text;

* according to the form of expression .

Electronic publications are divided into the following types:

* according to the availability of the print equivalent;

* by the nature of basic information;

\# according to the purpose;

\# according to the technology of distribution;

\# according to the character of communication between the electronic publication and the user;

\# according to the periodicity;

* according to the structure.

Currently, there is a typological model of Educational Publications, which includes four different types of publications, which include:

Programming-methodical (training plan and programs);

Educational-medical (methodical instructions, instructions);

Teacher (textbooks, manuals, lecture texts);

Auxiliary (practicum, issue and exercise sets).

At the same time, it is possible to include electronic educational publications that control this group - test programs and databases of those who were given.According to the structure electron publications are single-track (placed in one information carrier) and multi-track (numbered two or more independent electronic publications, each of which is placed in a separate information carrier)

So there is also a series of editions, consisting of a set of several roofs, which are extracted in the same format.

According to the form of statement of the material, electronic educational publications are divided into types convexion(function of providing information on education), programming(created using programming tools), problematic(based on the theory of problematic education and developing logical thinking) and universal(preserving individual elements of the listed models). According to its purpose, e-learning publications are divided into five main groups: for schoolchildren, for bachelors, for professionals, for Masters, for others.Depending on the availability of the printing equivalent is divided into two groups:- electronic analogue of the printed educational edition - electronic copy of the corresponding educational printed edition;- independent e-learning publication-an educational publication that does not have a print equivalent; .

By the nature of basic information, electronic publications are divided into the following types:

* text (marked) - basically stores textual information;

* fine electron edition - stores data consisting mainly of graphic images; 
* voice electronic publication - stores digital expression of voice information;

* software product-independent executable code;

* multimedia electronic publication-interconnected set of information of different nature

According to the distribution technology:

* local electron edition-electron edition, which is produced in a certain circulation and placed in a local information carrier;

* network electron Edition - an electronic edition distributed over a telecommunications network intended for a mass of unlimited users;

* combined electron Edition-both local and network-distributed electron edition.

According to the communication character between user and electron publication:

* electronic publications whose content and style of use is not altered by the user;

\# an electronic in which the content and method of use can be selected .

According to the technology of creation,electron publications are divided into types designed for pedagogical, teaching, controlling, demonstrative, auxiliary, as well as for training, modeling, management of the educational process, creation of programs for the educational purpose, selection of professions and training of children with disabilities in development.

The content of e-learning publications should be consistent with modern teaching technologies, taking into account the need for active use of computer technology in the educational process. E-learning publications are in history education.

The main requirements for educational literature in the humanitarian and socio-economic sphere are as follows:.

* To follow the printouts of historicism and traditionalism;

* Compliance with the standards of software and electron products;

\# compliance with aesthetic and ethical norms in the disclosure of information;

* Full and objective of bibliographic information;

The features of electronic educational publications in historical sciences include:

The main feature of humanitarian knowledge is that they are of a nonformal nature. Educational literature in the humanities is mainly in the form of text, it acquires a wide range of illusory information. This feature causes difficulties in the preparation of electronic educational publications, since the structuring process necessary for the hypertextual Organization of the reading material of such texts is difficult, requiring the authors of educational publications to have special didactic preparation. The main electronic educational publication in the teaching of historical sciences is a multimedia textbook. Its basis is hypertext, video and audio applications, animation, illustrative material of a large volume.

Electronic educational publications in historical sciences are multifunctional and are designed for different categories of educators. Their hypertensive structure allows you to fill the standard training material with special training blocks.For example, a history course designed for students studying in the field of physics can be held in the Department of history of Science and technology, and a history course for philologists can keep within themselves the Departments of history of culture, etc. The Internet Network creates great opportunities for the creation of electronic educational publications. The nature of electronic publications makes it possible to apply directly to special pages on the Internet within them and helps to create the necessary skills of readers-students to search for the necessary information in the field.

Electronic educational publications in the historical sciences should be created as educational-methodical journals, that is, they should keep in themselves a Bank of chrystomatics, praktikum, a dictionary, a test program, as well as control questions and tasks, along with a textbook.

The main type of educational process is lectures. Lecture is a form of Organization of the educational process that forms the knowledge, which is the guiding basis for the educational material to be mastered by the students. There are three main types of lectures, these are introductory lectures, informative lectures and obzor lectures.Based on the subject of the studied science and didactic purposes, the following forms of lectures can be used: problematic lectures, visual lectures, press conference lectures and hokazo.Ma electronic learning publications used in the Rozas should enrich the outlined material with videotapes, sound animated rollers, helping the speaker demonstrate complex processes.

The following types of elekctron learning prose can be used in the organization of theoretical material learning:

The lecture is recorded using a video camera.The winning side of this type of lecture is that there is an opportunity to stop at difficult and difficult places where it is possible to repeat at the time of doing it.

Multimedia lecture.For independent education, instructional interaktiv programs can be created.With the use of such teaching aids, each student can choose a learning exercise that is convenient for him, the optimal pace and method of learning. The indicator of mastering can also be raised to the account of controlling instruments in many ways.

Traditional publications: electronic lecture texts, base spellings, methodological guides on the study of theoretical material, etc.

Practical training is a form of Organization of the educational process aimed at strengthening theoretical knowledge by discussing sources and solving practical issues.

Electron educational publications, used in practical exercises, should provide the learner with information on the subject, the mode of conduct of the training and its purpose, control the knowledge, provide the necessary theoretical material and practical instructions, evaluate the knowledge of the learner. For historians, the main form of practical training is considered to be seminar training. This form of Education formulate the research point of view with respect to educational 
and scientific material. Among the electronic educational publications that are used in the Seminar sessions, it is possible to include abstracts, collections of documents and materials, base outline of lectures, electron textbook, etc. The introduction of information technology into the educational process is accompanied by an increase in the volume of students ' independently mastered knowledge.In fact, all existing types of e-learning publications can become the basis for the organization of Independent Education. In this process, the use of information technology is used in electronic publications, Internet resources, electronic databases, libraries, directories and funds, archives, etc.

The independent training of students on the basis of Information Technology includes the following: working with electron textbook, watching video collections, listening to audio cassettes, working with computer simulators, passing computer tests, etc.

\section{REFERENCES}

1. Kuronov.D. Introduction to Literary Studies.- Andijan: Hayot, 2002; T .: Folk heritage, 2004; T: Science, 2007

2. Shomaksudov A., Rasulov I., Kungurov R., Rustamov H. Stylistics of the Uzbek language. - Tashkent: 1974, p. 236

3. Kungurov R. Visual aids of the Uzbek language. - Tashkent: Science; 1977

4. Kungurov R., Begmatov E., Tojiev Y. Fundamentals of Speech Culture and Methodology.- Tashkent: Science, 1992 